\title{
A STUDY OF ARTERIAL SUPPLY OF CAECUM IN HUMANS.
}

\author{
Hosmani Veeresh'1 ${ }^{1}$ Halasagi S. S², Shakuntala R. Pai, G. F. Mavishettar
}
1. Assistant Professor, Dept. of Anatomy, Srinivas Institute of Medical Sciences and Research Center, Mukka, Mangalore.
2. Associate Professor, Dept. of Anatomy, Srinivas Institute of Medical Sciences and Research Center, Mukka, Mangalore.
3. Professor \& HOD, Dept. of Anatomy, Srinivas Institute of Medical Sciences and Research Center, Mukka, Mangalore.
4. Professor, Dept. of Anatomy, JJM Medical College.Davanagere

\section{CORRESPONDING AUTHOR}

Dr. Hosmani Veeresh, Assistant professor, Dept. of Anatomy, Srinivas institute of medical sciences and Research Center.

Mukka, Mangalore

E-mail: drveeresh77@gmail.com,

Ph: 009108904390833

\begin{abstract}
The surgical procedures on the caecum demand a precise knowledge of vascular anatomy of ileocolic region. The aim of this study is to study the arterial supply of the caecum, findings of which may reveal more anatomical facts about the arteries of caecum and their variations. Total 52 specimens of caecum and appendix with their arteries intact were collected, cleaned and dissected. The ileocolic artery and its branches to the caecum, and ileum were traced carefully and observations were recorded. The ileocolic artery arises independently from superior mesenteric artery in $96.88 \%$ of cases and ends by dividing into superior and inferior division in $93.76 \%$ of cases. The anterior and posterior caecal arteries arise by a common trunk in 56.25\%. The ileocolic artery arises from the superior mesenteric artery independently in $96.88 \%$ and terminates into superior and inferior division in $93.76 \%$ of cases. Common caecal artery seen in $56.25 \%$ of cases, arises from inferior division $(43.75 \%)$, superior division $(9.38 \%)$ and ileocolic artery (3.12\%).Anterior caecal artery arises from superior division (12.5\%), inferior division (15.63\%), ileocolic artery (3.12\%), ileal branch (6.25\%) and arterial arcade (6.25\%).The posterior caecal artery arises from superior division (18.76\%), inferior division (9.38\%), ileal branch (3.12\%), ileocolic artery (3.12\%), arterial arcade $(6.25 \%)$ and from ascending colic branch of inferior division (3.12\%). $21.87 \%$ of cases showed additional anterior and posterior caecal arteries.
\end{abstract}

KEYWORDS: Caecum, ileocolic artery, anterior caecal artery, posterior caecal artery.

INTRODUCTION: Holstead, a pioneer American surgeon has said that the best way to avoid injury to the blood vessel is to know how, when and where to ligate them. The responsibility of studying the arterial variations lies with the anatomists, the knowledge of which helps the surgeons.

Caecum has got great importance because it is prone for many pathological conditions. So surgical procedures on caecum demand a precise knowledge of vascular anatomy of ileocolic region. Literature pertaining to the vascular anatomy of caecum is vast in western population. There is need for the study on Indian population. In the present study an attempt is made to study the variations of arteries supplying caecum.

Journal of Evolution of Medical and Dental Sciences/Volume1/Issue5/November-2012Page-811 
MATERIALS AND METHODS: The arterial supply of the caecum was studied in 52 specimens. The specimens (caecum with appendix and part of ascending colon and ileum) were collected with their arteries intact from the postmortem centre and dissection hall (Department of anatomy), of J.J.M medical college Davangere and S.I.M.S \& R.C Mangalore.

Thus collected specimens were preserved in $5 \%$ formalin. After the preservation the specimens were dissected cleaned and numbered. The ileocolic artery and its branches to the caecum were traced carefully and observations were recorded.

RESULTS: The arterial supply of human caecum was studied by dissection method in 52 specimens. All the branches of the ileocolic artery have been dissected and traced till their termination with special attention to the caecal branches and variations have been noted down.

ORIGIN OF ILEOCOLIC ARTERY: In the present study the ileocolic artery originated from the superior mesenteric artery in 50 specimens (96.15\%) and in 2 specimens (3.84\%) it was originating in common with the right colic artery.

TERMINATION OF ILEOCOLIC ARTERY: The ileocolic artery ends by dividing into superior and inferior divisions in 50 specimens (96.15\%); into ascending colic, common caecal and ileal branches in 1 specimen (1.92\%); and into anterior caecal, posterior caecal, appendicular and ileal branches in 1 specimen (1.92\%).

COMMON CAECAL ARTERY: The common caecal artery arises from inferior division in majority of cases 48 specimens (92.30\%); from superior division in 3 specimens (5.76\%) and from ileocolic artery in one specimen $(1.92 \%)$.

ANTERIOR CAECAL ARTERY: The anterior caecal artery arises from the common caecal artery in 30 specimens (57.69\%); inferior division in 10 specimens (19.23\%); superior division in 7 specimens (13.46\%); ileal branch and arterial arcade in 2 specimens each (3.84\%) and in one specimen directly from ileocolic artery (1.92\%).

One specimen showed an additional anterior caecal artery (1.92\%).

POSTERIOR CAECAL ARTERY: The posterior caecal artery arises from the common caecal artery in 30 specimens(57.69\%);superior division in 12 specimens (23.07\%);inferior division in 5 specimens (9.61\%); ileocolic artery, ascending colic branch of inferior division and ileal branch in one specimen each $(1.92 \%$ each) and from an arterial arcade in 2 specimens $(3.84 \%)$.

3 specimens showed additional posterior caecal arteries (5.765).

2 specimens showed two anterior and two posterior caecal arteries (3.84\%).

DISCUSSION: In the present study, 52 specimens were studied for the arteries supplying the human caecum. The findings of the study have been compared with those of previous workers on the subject.

ORIGIN OF ILEOCOLIC ARTERY: In the present study the ileocolic artery originated from the superior mesenteric artery in 50 specimens (96.15\%) and in 2 specimens (3.84\%) it was 
originating in common with the right colic artery. Barry j.Anson ${ }^{1}$ mentions the origin of ileocolic artery independently from the superior mesenteric artery in 65\% of cases and in 35\% of cases it arises in common with the right colic artery. The origin of ileocolic artery either independently or in common with the right colic artery has also been mentioned byPiersol ${ }^{2}$,and others $(3,4)$

TERMINATION OF ILEOCOLIC ARTERY: In our study, the ileocolic artery ends by dividing into superior and inferior divisions in 50 specimens (96.15\%); into ascending colic, common caecal and ileal branches in 1 specimen (1.92\%); and into anterior caecal, posteriorcaecal, appendicular and ileal branches in 1 specimen $(1.92 \%)$.

Solanke. T. $\mathrm{F}^{5}$ mentions that the division of ileocolic artery into medial and lateral branches of unequal caliber is found in only $15 \%$ of cases; remaining $85 \%$ of the cases it remains single. Cunnigham ${ }^{3}$ illustrates the termination of ileocolic artery into ascending and descending branches.

Michel R B ${ }^{4}$ also describes the termination of the ileocolic artery into ascending colic and the descending branch which divides into anterior caecal, posterior caecal, appendicular and ileal branches. Patrick $\mathrm{W}^{6}$ states the termination of the ileocolic artery into colic and ileal branches, which is similar to findings of the present study.

In the present study in one specimen (1.92\%) the ileocolic terminates by dividing into ascending colic, common caecal, and ileal branches. The findings are similar to the same finding by,Schaffer ${ }^{7}$,Vandamme J P ${ }^{8}$ and others $\left(2,9\right.$ )Grant's ${ }^{10}$ states the similar pattern of division of ileocolic artery into four branches anterior caecal, posterior caecal, appendicular and ileal as in our present study.

COMMON CAECAL ARTERY: In the present study the anterior and posterior caecal arteries take their origin by a common trunk in 30 specimens(57.69\%).Piersol ${ }^{2}$, Anson and Mcvey ${ }^{11}$ mentioned the same in their study that the anterior and posterior caecal arteries arise by a common trunk (common caecal artery).Michel and co-workers 12 in their study found the anterior and posterior caecal arteries arising from a common trunk in $36 \%$ of cases. Ures et al. ${ }^{13}$ mentioned the same in $76.2 \%$ of cases and Bergmann ${ }^{14}$ in $13.5 \%$ of cases (unpublished report of Beaton, Anson, Swigart, and Jamieson).

ORIGIN OF COMMON CAECAL ARTERY (IN 57.69\%): In the present study, the common caecal artery arises from inferior division in majority of cases 26 specimens (50\%); from superior division in 3 specimens (5.76\%) and from ileocolic artery in one specimen (1.92\%).

Michel and co-workers 12 mentioned the origin of the common caecal artery from an arcade between colic and ileal branches in $76 \%$, less frequently from either ascending colic or ileocolic trunk. Anson and Mcvey ${ }^{11}$ have mentioned the origin of common caecal artery from the arcade between colic and ileal branches or separately from colic and ileal branches. Ures et al. 13 mentioned the origin of common caecal artery from the right colic artery in $15 \%$ and from the ileal branch in $61.2 \%$ of cases. Bergmann ${ }^{14}$ mentioned the origin of common caecal artery from the ileocolic artery.

\section{ANTERIOR AND POSTERIOR CAECAL ARTERIES}

\section{In the present study,}


The anterior and posterior caecal arteries arise from a common trunk(common caecal artery) in 30 specimens(57.69\%) The anterior and posterior caecal arteries had separate origin without a common trunk in 22 specimens (42.30\%).

The various sources of anterior and posterior caecal arteries are as follows:

ORIGIN OF ANTERIOR CAECAL ARTERY: The anterior caecal artery arises from the common caecal artery in 30 specimens (57.69\%); inferior division in 10 specimens (19.23\%); superior division in 7 specimens (13.46\%); ileal branch and arterial arcade in 2 specimens each $(3.84 \%)$ and in one specimen directly from ileocolic artery (1.92\%).

ORIGIN OF POSTERIOR CAECAL ARTERY: The posterior caecal artery arises from the common caecal artery in 30 specimens(57.69\%);superior division in 12 specimens (23.07\%);inferior division in 5 specimens (9.61\%); ileocolic artery, ascending colic branch of inferior division and ileal branch in one specimen each (1.92\% each) and from an arterial arcade in 2 specimens (3.84\%).

Schaffer ${ }^{7}$ and several other workers $(1,4,15,16,17)$ have mentioned that the anterior and posterior caecal arteries originate directly from the ileocolic artery.

Michel and co-workers ${ }^{12}$ stated that the anterior and posterior caecal arteries arise separately in $64 \%$ of cases. The most common origin for both arteries is from an arcade in between colic and ileal branches in 76\%, less frequently from colic, ileal or ileocolic artery.

Hamilton ${ }^{18}$ has mentioned the origin of anterior and posterior caecal arteries from the inferior division of the ileocolic artery. Ures et al ${ }^{13}$ have mentioned the origin of anterior and posterior caecal arteries separately in $23.7 \%$. In $8.7 \%$ of cases the anterior caecal artery had its origin from the right colic artery and posterior caecal artery directly from the ileal branch. In $13.8 \%$ of cases both caecal arteries originated directly from the ileal branch and in $1.2 \%$ of cases the anterior caecal artery originated from the right colic artery and posterior caecal artery from the ileocolic artery. Bergmann ${ }^{14}$ mentioned the origin of both caecal arteries directly from the ileocolic artery in $28.5 \%$ cases and in $4 \%$ of cases from the arcade between right colic and ileal branches. Kozmithet al. ${ }^{19}$ mention the origin of both caecal arteries from the ileocolic loop formed between ileal and colic branches. Patrick $\mathrm{W}^{6}$ states the origin of both the caecal arteries from the ileal branch.

In the present study some of the specimens showed additional anterior or posterior caecal artery.

Specimen no.18 showed an additional anterior caecal artery from ileal branch. Specimen no. 1 showed additional posterior caecal artery from an arcade between posterior caecal and ascending colic branch. Specimen no.42 and 47 showed additional posterior caecal arteries from superior and inferior divisions respectively.

Anson and Mcvey ${ }^{11}$ described one anterior caecal and two posterior caecal arteries originating from an arcade by a common trunk. Bergmann ${ }^{14}$ mentioned the origin of three posterior caecal and one anterior caecal arteries from the ileocolic artery in $6.5 \%$ of cases (unpublished report of Beaton, Anson, Swigart and Jamieson).

CONCLUSION: In the present study on the arterial supply of human caecum shows that the origin of ileocolic artery is from the right side of the superior mesenteric artery independently and it terminates by dividing into superior and inferior divisions in majority of cases.

Journal of Evolution of Medical and Dental Sciences/Volume1/Issue5/November-2012Page-814 
There is common caecal artery in more than half of the cases (57.69\%), which originated from inferior division in 50\%; superior division 5.76\% ; and ileocolic artery in $1.92 \%$ of cases.

In $57.69 \%$ of the specimens the anterior and posterior caecal arteries originate from the common caecal artery. Other sites of origin for anterior caecal artery are superior division $13.46 \%$; inferior division $19.23 \%$; ileocolic artery $1.92 \%$; ileal branch and arterial arcade in 3.84 specimens each.

Other sites of origin of posterior caecal artery are superior division 23.07\%; inferior division 9.6\%; from ileocolic artery, ascending colic branch of inferior division and ileal branch in $1.92 \%$ each; from an arterial arcade in $3.84 \%$ of cases.

$7.69 \%$ of specimens showed additional anterior and posterior caecal arteries.

\begin{tabular}{|c|c|c|}
\hline Separately from superior mesenteric artery & 50 specimens & $96.15 \%$ \\
\hline In common with right colic artery & 2 specimens & $3.84 \%$ \\
\hline Superior and inferior division & 50 specimens & $96.15 \%$ \\
\hline Ascending colic, common caecal, \&ileal branches & 1 specimen & $1.92 \%$ \\
\hline $\begin{array}{l}\text { Anterior caecal, posterior caecal, appendicular \&ileal } \\
\text { branches }\end{array}$ & 1 specimen & $1.92 \%$ \\
\hline
\end{tabular}

\begin{tabular}{|l|l|l|}
\hline Superior division & 3 specimens & $5.76 \%$ \\
\hline Inferior division & 26 specimens & $50 \%$ \\
\hline Ileocolic artery & 1 specimen & $1.92 \%$ \\
\hline
\end{tabular}

\begin{tabular}{|l|l|l|}
\hline Common caecal artery & 30 specimens & $57.69 \%$ \\
\hline Ileocolic artery & 1 specimen & $1.92 \%$ \\
\hline Superior division & 7 specimens & $13.46 \%$ \\
\hline Inferior division & 10 specimens & $19.23 \%$ \\
\hline Ileal branch & 2 specimens & $3.84 \%$ \\
\hline Arterial arcade & 2 specimens & $3.84 \%$ \\
\hline
\end{tabular}

\begin{tabular}{|l|l|l|}
\hline Common caecal artery & 30 specimens & $57.69 \%$ \\
\hline Ileocolic artery & 1 specimen & $1.92 \%$ \\
\hline Superior division & 12 specimens & $23.07 \%$ \\
\hline Inferior division & 5 specimens & $9.61 \%$ \\
\hline Ileal branch & 1 specimen & $1.92 \%$ \\
\hline Arterial arcade & 2 specimens & $3.84 \%$ \\
\hline Ascending colic branch of inferior division & 1 specimen & $1.92 \%$ \\
\hline
\end{tabular}

\section{REFERENCES:}

1. Barry JA. Morri's Anatomy $12^{\text {th }}$ ed. Newyork. McGraw-Hill Book Company. 1966; p.744.

2. Piersol. Human Anatomy. Philadelphia. JB Lippincott Company. 1907.

3. Romanes GJ. Cunninghams's Text book of Anatomy $12^{\text {th }}$ ed. Wallan street Oxford. Oxford University press. 1981; p.926-27. 
4. Michael RBK, Norman SW. Surgery of Anus, Rectum and Colon. Vol. 1. Philadelphia. W.B. Saunders Company. 1993; p.11.

5. Solanke TF. The blood supply of Vermiform Appendix in Nigerians. J Ant 1968;102: p.353362.

6. Patrick WM, David HL, Martin AL, Anthony JS, Surgery of the colon, rectum and anus. $1^{\text {st }}$ ed. Philadelphia. W. B. Saunders Company. 199; p.18.

7. Schaffer WJ. Morri's Human Anatomy. 11 th ed. Toranto. 1953; p.709.

8. Vandamme JP, Bonte J. Anew look at the blood supply of the ileocolic angle. Acta Anat(Basel). 1982; 113(1): p.1-14.

9. Mcminn RMH. Last's Anatomy. 9th ed. Edinburgh. Churchill Livingstone. 1994; p.338-39.

10. Basmajian JV. Grant's method of Anatomy. $8^{\text {th }}$ ed. Calcutta scientific Book Agency 1972.

11. Anson BJ, McVey CB. Surgical Anatomy. $5^{\text {th }}$ ed. Philadelphia. W.B. Saunders Company 1971.

12. Michels NA, Siddharth P, Kornblith PL, Parke WW. The variant blood supply to the small and large intestines, its importance in regional resections. A new anatomic study based on 400 dissections with complete review of literature. J Int Coll Surgeons 1963; 39:p.127.

13. Ures J, Stacchini A, Prates JC, Gatto IM, Ures S. Angiographic anatomy of the cecal artery. ArqGastroenterol. 1979 Jan-Mar; 16(1):p.8-11.

14. Bergmann RA, Thompson SA, Afifi AK, Saadeh FA. Compendium of Human Anatomic Variation. $1^{\text {st }}$ ed. Munich. Urban Schwarzenberg. 1988; p.406.

15. Hollinshed WH. Anatomy for Surgeons. Vol.2, 1956; p.492-95.

16. Luzsa G. X-ray Anatomy of the vascular system London. Butterworth and Co. Ltd. 1974; p.237.

17. Simon AM, Birnbaum BA, Jacobs JE. Isolated infarction of the cecum: CT findings in two patients. Radiology 2000 Feb; 214(2): p.513-16.

18. Hamilton WJ. Text book of human anatomy. $1^{\text {st }}$ ed. London. Mac Millan and Company Ltd. 1976.

19. Kornith PK, Scot, Boley, Blain SW. Anatomy of the sphlanchnic Circulation. The surgical clinics of North America. Feb 1992; 72(1): p.12-15. 